\title{
Visible Light Fidelity Technology: Survey
}

\author{
Kawther Dawood Salman ${ }^{1}$, Ekhlas Kadum Hamza ${ }^{2}$ \\ ${ }^{12}$ Control \& System Engineering Dept, University of Technology, Baghdad, Iraq. \\ ${ }^{1}$ cse.19.02@grad.uotechnology.edu.iq, ${ }^{2} 100374 @$ uotechnology.edu.iq
}

\begin{abstract}
Wireless Fidelity (Wi-Fi) is particularly popular today. Every place has hotspots to access the internet via Wi-Fi, including homes, offices, colleges, and other public places. This increased number of users, and hence the use of bandwidth, has led to radio spectrum congestion. Thus, in the year of 2011, Light-Fidelity (Li-Fi) was introduced, which applies a visible light region for data transmission, to solve this radio crisis problem. This visible part of the spectrum was 10,000 times big compared to the part utilized in the Wi-Fi radio. Furthermore, Li-Fi was a sub-set of Visible Light Communication (VLC), using Light-Emitting Diode (LED) bulbs for transmitting data utilizing light-medium. This paper reviews the differences between Li-Fi technology and wireless types. It Also focuses on the architecture, components, functioning, modulation technologies, and applications of Li-Fi.
\end{abstract}

Index Terms-Li-Fi, VLC, Wi-Fi, LED, Photodetector, Optical wireless Communication

\section{INTRODUCTION}

The current era in digital wireless communication is on the edge of revolution. Li-Fi (Light Fidelity) is the superior modification of Wi-Fi. It is the latest and one of the greatest inventions of the 21st century. The idea behind this technology is that it is possible to transmit the information needed for communication by using Light-Emitting Diode (LED) whose intensity varies more quickly than the human eye that can sense, using a detector to capture that intensity. It is a form of Visible Light Communication (VLC) that is part of wireless optical communications [1] and could be a substitute for Radio Frequency (RF), i.e. Wi-Fi and cellular network communication. So far, this new Li-Fi technology is estimated to be more than 10,000 times faster than many implementations of Wi-Fi [2]. The ever-increasing number of users of mobile wireless networks necessitates a reduction in cell size to increase multi-user access capacity. Visible light is used as a transmission medium by Light-Fidelity (Li-Fi) technology. Li-Fi "attocells"-are cellular elements using preexisting indoor lighting that are smaller than typical radio frequency elements. Each LED turns into a wireless access point (AP) in addition to each light and serves several user devices that are linked to a given optical attocell. Li-Fi will be a key component for the future of the fifth-generation (5G) because of its benefits, such as very high bandwidth, high energy efficiency, and improved safety [3] [4] [5]. The technology of VLC might be considered as a complement to present wireless Radio Frequency (RF) communications since it uses visible light in a range of $(380$ and $780 \mathrm{~nm})$ as a carrier of data. Also, the visible light spectrum was un-regulated rather than the RF spectrum, thus, it is cheap compared to RF communications. VLC might provide data rates of higher or a maximum of $1 \mathrm{~GB} / \mathrm{s}$. Also, there might be an increase in VLC data rates utilizing Multiple Input Multiple Output (MIMO) methods [6], as they are enabling the VLC to be part of the 5G technology. About RF, in which cancer might be caused by radio waves, however, VLC is considered to be safe for the health of humans. The VLC might be utilized where using RF (nuclear plants, hospitals, and airplanes) was restricted. Since it doesn't require more 
DOI: https://doi.org/10.33103/uot.ijccce.21.2.1

energy for transmitting data, VLC is energy effective. The same source of light is utilized as a data carrier and for illumination, whereas the RF waves are capable of penetrating through non-metallic materials, the visible light might have the ability of just penetrating transparent materials which limits coverage area or mobility, at the same time, preventing the occurrence of eavesdropping. VLC might be applied for providing high data rates for indoor broadcasting or internet connections, whereas VLC might be applied for communication between the vehicles and/or the traffic infrastructure as well as vehicles for outdoor applications. The main issue in indoor applications is to provide rapid internet services, whereas the issue in automotive applications achieves long-distance communications. [7]

The other parts of this study are provided as follows: section II is presenting a previous study on Li-Fi technology (VLC). Section III provides a brief description of some types of wireless networks, it summarizes the differences between them, and in the IV section, we explain the $\mathrm{Li}-\mathrm{Fi}$ architecture. The components of $\mathrm{Li}-\mathrm{Fi}$ are explained in section $\mathrm{V}$, while Section VI shows its operation. Li-Fi technology advantages and a review of Li-Fi features over Wi-Fi are provided in Section VII, respectively. In Section VIII, problems with Li-Fi are explained. Section IX shows Li-Fi modulation techniques, and Section X displays Li-Fi applications. Finally, conclusions are drawn in Section XI and the sources in Section XII.

\section{LITERATURE SURVEY}

This section summarizes the comparison of previous ideas and research related to Li-Fi visible light technology, as shown in Table 1.

TABLE (1) SuMMARY OF LiterATURE REVIEW

\begin{tabular}{|c|c|c|}
\hline Title & Authors & Research Concept(s) \\
\hline $\begin{array}{l}\text { Asynchronous indoor } \\
\text { positing system based } \\
\text { on visible light } \\
\text { communication }\end{array}$ & $\begin{array}{c}\text { In } 2014 \\
\text { Weizhi Zhang et } \\
\text { al. [8] }\end{array}$ & $\begin{array}{l}\text { Discussed the Use asynchronous intern Visible Light Communication } \\
\text { (VLC) based positioning system technology. Using the Basic Frame } \\
\text { Slotted Aloha (BFSA) protocol as a solution to the problem of multi- } \\
\text { channel access. After analyzing the noise related to internal } \\
\text { environments with indirect and direct exposure to sunlight, the results } \\
\text { found that indoor positioning service was up to } 95 \text { percent precision at } \\
\text { assuming direct sunlight exposure of } 17.25 \mathrm{~cm} \text { and } 95 \text { percent precision } \\
\text { at assuming indirect sunlight exposure of } 11.2 \mathrm{~cm} \text {. }\end{array}$ \\
\hline $\begin{array}{l}\text { MIMO VLC positioning } \\
\text { system based on LEDs } \\
\text { utilizing diversity } \\
\text { reception technology }\end{array}$ & $\begin{array}{l}\text { In } 2015 \text { Y. Zhou } \\
\text { et al. [9] }\end{array}$ & $\begin{array}{l}\text { Talked about using a method for Visible Light Communication } \\
\text { (VLC) Positioning System based on Light-Emitting Diode (LED) that } \\
\text { combines the technology of Multiple-Input Multiple-Output (MIMO) } \\
\text { with the technology of diversity reception and shows that the use of } \\
\text { such a method might have a positive impact on the performance } \\
\text { reception. It can also be very practical to use the best reception area } \\
\text { and lamp spacing and half the half-angle related to power and the } \\
\text { distance between } 2 \text { receptors. }\end{array}$ \\
\hline $\begin{array}{l}\text { Adaptive correction } \\
\text { model for indoor MIMO } \\
\text { VLC using positioning } \\
\text { technique with node } \\
\text { knowledge }\end{array}$ & $\begin{array}{c}\text { In } 2015 \text { Tran } \\
\text { The Son et al. } \\
{[10]}\end{array}$ & $\begin{array}{l}\text { Examined the new model for adaptive correction for the recovery } \\
(4 \times 4) \text { Visible Light Communication- Multiple-Input Multiple-Output } \\
\text { (MIMO VLC) data for missing transmitter pilot signals. To predict the } \\
\text { current site, the well-known trigonometric technique was introduced } \\
\text { with receptor knowledge of user locations. The results showed that a } \\
\text { free error was received in the data transmission across the four } \\
\text { channels, providing Multiple Input Multiple Output Visible Light } \\
\text { Communication (MIMO VLC) links smoother and better than other } \\
\text { proposed models. }\end{array}$ \\
\hline $\begin{array}{l}\text { Optical MIMO-OFDM } \\
\text { with generalized LED } \\
\text { index modulation }\end{array}$ & $\begin{array}{l}\text { In } 2017 \text { A. } \\
\text { Yesilkaya et } \\
\text { al.[11] }\end{array}$ & $\begin{array}{l}\text { The author shows a new way For Multiple Input Multiple Output- } \\
\text { Orthogonal Frequency Division Multiplexing (MIMO-OFDM)based } \\
\text { Visible Light Communication (VLC) systems to circulate light-emitting } \\
\text { diode (LED) index modulation methods. This was achieved through } \\
\text { multiplexing the exploitation along with the modulation of the Light- }\end{array}$ \\
\hline
\end{tabular}


DOI: https://doi.org/10.33103/uot.ijccce.21.2.1

Emitting Diode (LED) index.

Analysis of received

power characteristics of

commercial photodiodes

in indoor Los channel

In 2017 S. Fuada

et al. [12]

visible light

communication
Discussed the Method for investigating the receptor characteristics of many commercially available Los-channel photovoltaic Visible Light Communication (VLCs). The results indicated that the Field Of View (FOV) did not affect the character of the If the ( $\mathrm{n}$ factor) refractive index is overlooked, the receiving power.
Indoor positioning using a

single transmitter for a

visible light

communications system
In 2017 Mustafa

Al-Nassrawi et

al.

[13]

Explained a new way of estimating the receptor position in the Visible Light Communication (VLC) system, where it works by using minimum transmitters to place it in a single channel or Multiple Input Multiple Output-Visible Light Communication (MIMO-VLC) system. The technique is based on user speed estimation between past and current positions. Compared to current positioning methods such as triangulation, the evaluated speed, and received signal strength (RSS) were acquired from the single transmitters for determining the location of the user, the simulation results showing that the approach was efficient in acquiring the user's position.

Visible light

communications-based

indoor positioning via

compressed sensing
In $2018 \mathrm{~K}$. Gligori' et al. [14]
The Authors show the Visible Light Communication (VLC) based method of internal positioning using the compressed sensor. It is considered that with a photodiode, a large number of Light-Emitting Diode (LEDs) convey their position information and the user's device.
3D Indoor visible light positioning system using RSS ratio with neural In 2018 Sheng network
Discussed the internal 3D VLP system that uses a Neural Network-based Position Estimator for Received Signal Strength (NNPE RSS) ratio measurements, the neural network-based position estimator (NNPE) system provides high-resolution 3D positioning features without knowing the Light-Emitting Diode (LED) transmitter coordinates and the Model on irradiation.
An indoor visible light positioning system using an artificial neural network
In 2018 Chun

Lin et al. [16]
Examined the use of the Visible Light Positioning System method depends on connections to the Artificial Neural Network (ANN) and the optical camera.
Performance comparison

of MIMO cap receivers

in visible light

communication
In 2018 Kabiru

O. Akande et al [17]

Talked about Using less amplitude and phase Multiple Inputs Multiple Output-Conventional Carrierless Amplitudes (MIMO CAP) low-complex detection schemes in the multiple-input multiple-output carrier and comparing their performance to optimum ML detector performance. Also, the detection schemes Minimum Mean Square Error Detection With Optimally-Ordered Successive Interference Cancellation (MMSE-OSIC) and OSIC have been identified for providing considerable performance improvements on the respective linear detection devices MMSE.

The author shown Using various photovoltaic modules as

An OFDM testbed for Li-

Fi performance

characterization of

photovoltaic modules
In $2018 \mathrm{~N}$.

Lorri ere Aix

Marseille Univ

et al. [ 18] photodetectors to discuss the performance of the Light Fidelity (Li-Fi) obtained from the Orthogonal Frequency-Division Multiplexing (OFDM) based light fidelity (Li-Fi) test. For system configuration, the DC biased optical orthogonal frequency-division multiplexing (DCOOFDM) scheme was chosen under the same conditions as light fidelity (Li-Fi) data transfers.

Examined the visible light communication (VLC) system that has a $15.73 \mathrm{~Gb} / \mathrm{s}$ of data rate following applying a forward error correction (FEC) to a link of $1.60 \mathrm{~m}$. The wavelength-division multiplexing (WDM) system was designed with four wavelengths of visible light based on double-colored mirrors, and each one of the wavelengths was formative utilizing DC biased Optical Orthogonal Frequency-Division Multiplexing (DCO-OFDM) with adaptive bit loading as well as optimized system parameters, while $15.73 \mathrm{G}$ bit / s as data transfer rate 


\begin{tabular}{|c|c|c|}
\hline & & $\begin{array}{l}\text { is reached with bit error rate (BER), not more than } 7 \% \text { Hard-Decision } \\
\text { Forward Error Correction Coding (HDFEC) limit of } 3.810-3 \text { on a 1.6- } \\
\text { meter wireless connection. }\end{array}$ \\
\hline $\begin{array}{l}\text { Impact of device } \\
\text { orientation on error } \\
\text { performance of Li-Fi } \\
\text { systems }\end{array}$ & $\begin{array}{l}\text { In } 2019 \text { M. D. } \\
\text { Soltani et al. } \\
{[20]}\end{array}$ & $\begin{array}{l}\text { The Author presented the likelihood probability density function } \\
\text { (PDF) derivation related to Signal to Noise Ratio (SNR) for the } \\
\text { randomized devices based on derived PDF where bit error rate (BER) } \\
\text { performance of the DC biased optical Orthogonal frequency-division } \\
\text { multiplexing (DCO-OFDM) in the Additive white Gaussian noise } \\
\text { (AWGN) channel is evaluated using randomized user equipment } \\
\text { (UEs). With the exact criterion, the average bit error rate (BER) is } \\
\text { rounded roughly at random and precisely matches and thus investigates } \\
\text { the role of the angle which ensures the presence of a Line Of Sight } \\
\text { (LOS) link in the user equipment -Field Of View (UE-FOV). The huge } \\
\text { effect of optimal bias toward the access point on Bit Error Rate (BER) } \\
\text { performance is also examined. }\end{array}$ \\
\hline $\begin{array}{l}\text { Performance Analysis } \\
\text { of DC-OFDM } \\
\text { Modulation Scheme in } \\
\text { Li-Fi Communication } \\
\text { System. }\end{array}$ & $\begin{array}{l}\text { In } 20^{r} \cdot \text { Kumari, } \\
\text { Shivendra DIpa } \\
\text { Singh, [21] }\end{array}$ & $\begin{array}{l}\text { Discussed the Presents a DC biased optical Orthogonal } \\
\text { Frequency-Division Multiplexing (OFDM) modulation-based Multiple } \\
\text { Input Multiple Output (MIMO) system utilized for the technology of } \\
\text { the light fidelity (Li-Fi). Also, the design has been used for the } \\
\text { calculation of the system's receiver power and output signal. The } \\
\text { received power reaches its maximum value of } 3.5^{*} 10^{\wedge}-5 \text { at } 0 \text { surface } \\
\text { length. }\end{array}$ \\
\hline
\end{tabular}

\section{WIRELESS TECHNOLOGIES}

This section presents deceive Wi-Fi, Bluetooth, Li-Fi, and Zig-Bee wireless protocol that has IEEE802.15. 7 standards, $802.11 \mathrm{a} / \mathrm{b} / \mathrm{g}$ standards, 802.15.4, and 802.15.1 while IEEE standards defended just MAC and physical layer.

\section{a. Li-Fi}

The Li-Fi represents IEEE802.15.7 Standard Light-Fidelity. It has been applied for Personal Area Wireless (PAN) networks. Data parallels are transmitted to the array of LEDs, which data rate speeds are $10 \mathrm{Gbps}$ [22].

\section{b. Wireless Fidelity (Wi-Fi)}

Wi-Fi is considered as one of the major wireless networks following the IEEE standard $802.11 \mathrm{n} / \mathrm{a} / \mathrm{b} / \mathrm{g}$ for WLANs. Users are enabled for browsing the Internet and connecting the cloud at broadband speeds (offered via network vendor) [23] [24].

\section{c. Bluetooth}

Bluetooth is developed for replacing cables about PC peripherals with low-cost and short-range devices. It is operating in a frequency band of $2.4 \mathrm{GHz}$, and a maximum capacity of $720 \mathrm{Kbps}$ might be shared via devices within 10 meters of each other. Its disadvantage is that maximum of 8 devices communicating on a single network [25] [26].

\section{d. ZigBee}

The Zig-Bee transceivers operate on unlicensed scientific, industrial, as well as Industrial, Scientific, Medical (ISM) radio spectrums. 16 channels, every one of which supports 250 data rates, were assigned at $2.4 \mathrm{GHz}$ [27] [28].

Table 2 is summarizing the 4 wireless protocol types, each one of the protocols is deriving the standards of IEEE, security, costs, normal range, frequency bandwidth, data transmission speed, network topology, power consumptions, and year of manufacture. 
DOI: https://doi.org/10.33103/uot.ijccce.21.2.1

Table (2) Relation of the Li-Fi, Bluetooth, ZigBee, Wi-Fi, With a Protocol Wireless [22]

\begin{tabular}{cccccc}
\hline $\begin{array}{c}\text { Sequence } \\
\text { of } \\
\text { numbers }\end{array}$ & Parameters & Li-Fi & Wi-Fi & Bluetooth & ZigBee \\
\hline I & Standard IEEE & 802.15 .7 & $802.11 \mathrm{a} / \mathrm{b} / \mathrm{g}$ & 802.15 .1 & 802.15 .4 \\
\hline II & Mode of Operation & $\begin{array}{c}\text { Utilizing light } \\
\text { waves }\end{array}$ & $\begin{array}{c}\text { Utilizing } \\
\text { radio waves }\end{array}$ & $\begin{array}{c}\text { Utilizing short- } \\
\text { wavelength UHF radio } \\
\text { waves }\end{array}$ & $\begin{array}{c}\text { Utilizing radio } \\
\text { waves }\end{array}$ \\
\hline III & Speed Transfer Data & $1 \mathrm{G} \mathrm{bps}$ & $150 \mathrm{Mbps}$ & $25 \mathrm{Mbps}$ & $250 \mathrm{k} \mathrm{bit/s}$ \\
\hline IV & Frequency Bandwidth & $10000 \mathrm{GHZ}$ & $\begin{array}{c}2.40 \mathrm{GHz}, \\
4.90 \mathrm{GHz} \\
\text { and 5.0GHz }\end{array}$ & $2.4-2.485 \mathrm{GHz}$ & $2.4 \mathrm{GHz}$ \\
\hline V & Network Topology & Point to point & $\begin{array}{c}\text { Point to } \\
\text { point }\end{array}$ & Piconet & Start \\
\hline VI & Range & $10 \mathrm{~m}$ & $10-100 \mathrm{~m}$ & $10 \mathrm{~m}, 100 \mathrm{~m}, \mathrm{Based} \mathrm{on}$ \\
classes & $10-100 \mathrm{~m}$ \\
\hline VII & Power Consumption & Low & Medium & High & High \\
\hline VIII & Cost & Low & High & High & High \\
\hline IX & Year & 2001 & 1990 & 1998 & Not \\
\hline X & Security & Highly & Less & Less \\
\hline
\end{tabular}

\section{THE ARCHITECTURE OF Li-Fi}

The li-Fi architecture was classified according to layers as seen in Fig.1. Li-Fi is composed of 3 layers i.e. Physical layer (PHY layer), Media Access Control Address (MAC layer), and Application layer. IEEE802.15.7 is defining just 2 layers, MAC and Physical [29].

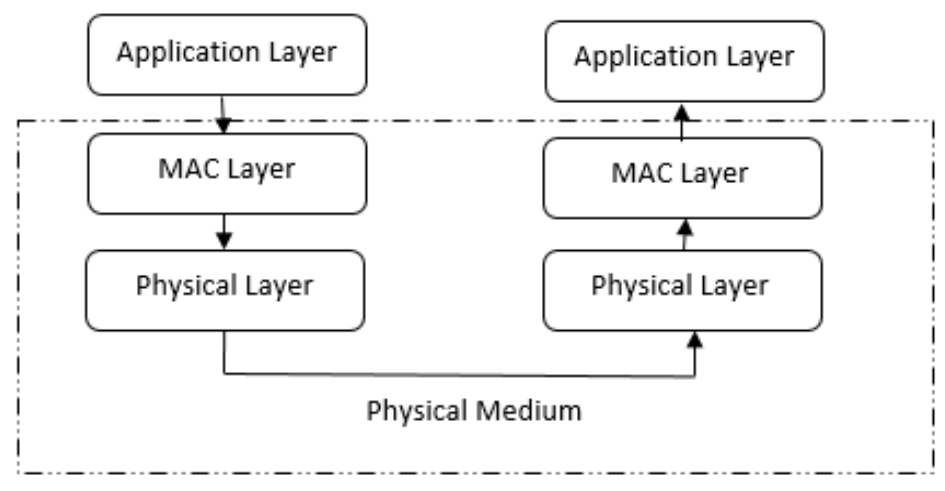

Fig. 1. LAYERED ARCHITECTURE Li-Fi (IEEE802.15.7) [29]

\section{a. IEEE 802.15.7 Protocol}

In this IEEE standard, a PHY (Physical I, II \& III) and a MAC layer are defined in an optically transparent media for short-range visible light communications. The visible light spectrum wavelength stretches from $380 \mathrm{~nm}$ up to $780 \mathrm{~nm}$. This can deliver the data high enough for supporting the multimedia audio and video operations, and also takes into account mobility, infrastructure compatibility, and ambient light noise interference [29].

\section{b. Li-Fi physical layer}

Many things are responsible for the physical layer, or the PHY layer. It handles data forwarding and reception. The physical layer of Li-Fi contains three layers, as detailed in Table 3. [29] 
TABLe 3. Physical Layers of Li-Fi [29]

\begin{tabular}{cccc}
\hline $\begin{array}{c}\text { Sequence of } \\
\text { numbers }\end{array}$ & Operating Modes & Applications & Data rates \\
\hline I & PHY I & Outdoors application 1 & $11.67-267.6 \mathrm{Kbit} / \mathrm{s}$ \\
\hline II & PHY II & Indoors application & $1.25-96 \mathrm{I} \mathrm{Mbit/s}$ \\
\hline III & PHY III layer & Color Shift Keying (CSK) & $12-96 \mathrm{I} \mathrm{Mbit/s}$ \\
\hline
\end{tabular}

\section{Li-Fi SYSTEM COMPONENTS}

The presented section is providing different $\mathrm{Li}-\mathrm{Fi}$ system components:

\section{a. Light-Emitting Diode ( transmitter)}

In general, transmitters are devices used to transmit information via a medium. The transmitter takes the signal into the input and creates something which can reach the receiver in output. For example, the radio techniques communicate with an antenna that generates an electromagnetic field, the VLC communicates with a light source that can vary its power, even the human throat could be seen as a transmitter that generates an audible signal. The transmitter can be of many types. For VLC the transmitter should be a device capable of manipulating the visible light to generate a signal that can be interpreted from a receiver. The Optical Wireless Communications (OWC) technologies generally use two devices as a light transmitter: LED and LD [30]. VLC LEDs appear to be the best choice, the LED devices are cheap and are not harmful to the eyes of LDs [31]. LED can be defined as one of the semiconductor devices emitting light in the case when passing an electrical current through it. Also, the light is generated in the case when particles that are carrying current (holes and electrons) are combining in the material in semiconductor, while the light wasn't explicitly bright, yet it was monochromatic in the majority of LEDs that happen at a single wavelength [32]. In comparison to Infrared Radiation (IR) LED producing a single data stream with $10 \mathrm{kbps}-20 \mathrm{kbps}$ speed, such LEDs are generating thousands of data streams that spread through the room, in which the light might be reaching extremely rapid rates [9]. Via utilizing certain techniques of Luminaire Design Optimization, the possibility of such LED might be increasing. The R\&D center related to pure VLC has lately achieved a $3.5 \mathrm{Gbps}$ data rate from single color micro-LED operate at $5 \mathrm{~mW}$ with a distance of $1 \mathrm{~m}$ and $1.1 \mathrm{Gbps}$ as data rate at $10 \mathrm{~m}$ and $5 \mathrm{~mW}$ [9]. Therefore, it might be indicated that data rates of over $10 \mathrm{Gbps}$ might be reached via utilizing 3 Red Green Blue (RGBO LED colors [33]. Fig.2 shows how the LED works. 
DOI: https://doi.org/10.33103/uot.ijccce.21.2.1

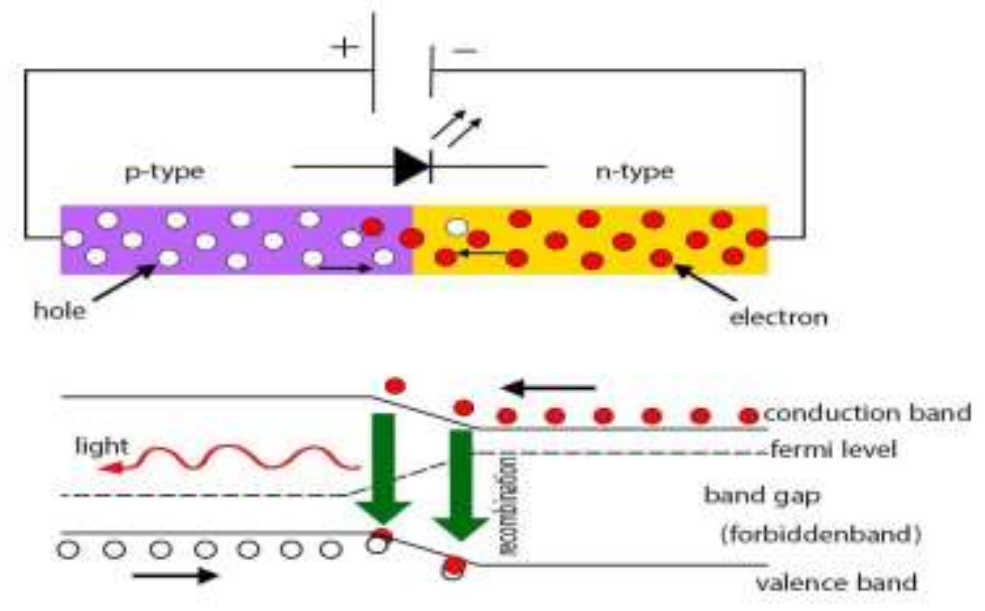

FIG. 2. PRINCIPLE OF LED WORKING

A very important design requirement for VLC is lighting, which is the primary function of the LED lamps, it should not be compromised for communication purposes because of its use. The VLC system's performance is therefore directly proportional to how the LED lamps are designed. The reason why white light is the most frequently used form of indoor and outdoor lighting is that the colors of objects are closely related to the colors of the same objects under the sunlight as seen under white lights [33]. White light is normally generated via one of the following methods in solid-state lighting:

- Blue LED with phosphorus: In this method, white light is generated by coating a blue LED with a layer of yellow phosphorus, producing white light when the blue light passes through the yellow phosphorus. By modifying the phosphor coating thickness, different variants of white light can be generated.

- RGB Combination: White light is also provided by a combination of red, green, and blue LEDs. However, this method is more costly than the first one. These methods can be seen in Fig 3.
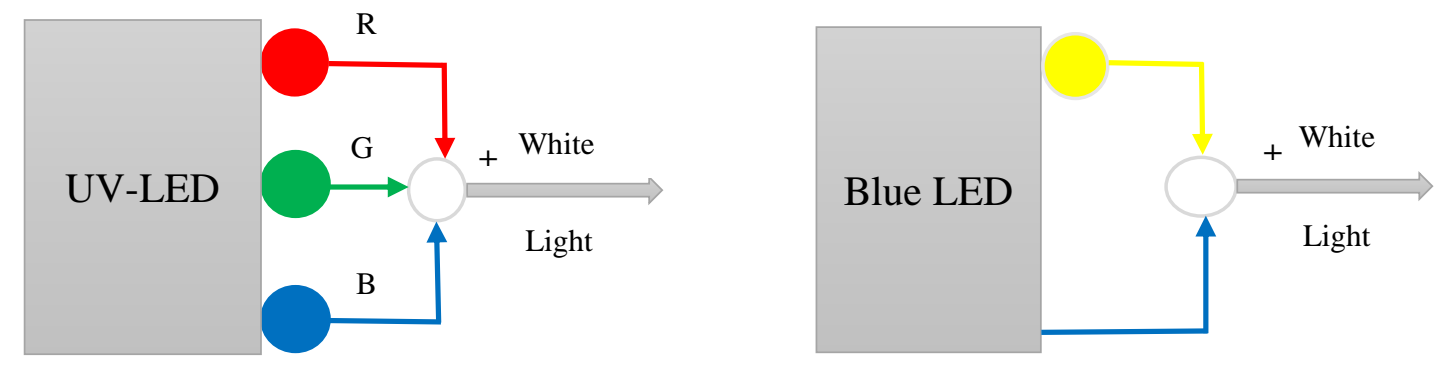

Fig. 3. MethodS USED IN PRODUCING White Light [33]. 
DOI: https://doi.org/10.33103/uot.ijccce.21.2.1

\section{b. Photodiode ( Receiver )}

A photodiode is an instrument that helps to transform light into an electrical current. This is made of semiconductor material and is intended to work in reverse bias, containing a p-n junction. In the photodiode, the current is propagated when photons are absorbed, and when there is no existing light, a very small amount of current is also propagated. Photodiodes have lingering response times, accompanied by an increase in surface area. Because of its low cost and normal rugged structure, photodiode technology was victorious and widely used. Photodiodes have two distinct modes of operation, firstly PV (photovoltaic) mode and second photoconductive mode. In the former mode, credence in the light was nonlinear, while the reached dynamic range was small, and in PV (photovoltaic) mode, the maximum speed isn't obtained either. In the latter, credence on light was extremely linear and opposite voltage imposes no considerable effect on light, yet its effect is weak on the dark current (presented reached with no light) [32]. Also, the parameters associated with the receiver involve the photodiode's physical area, and Field Of View of the receiver (FOV), detector's sensitivity, and so on. Typically, the receiver is going to utilize the assembly approach for suppressing stray light noise and allow the required optical signals for being optimally detected. Also, optical lenses, optical concentrators, light filters, and amplifiers connected to its rear-end are majorly involved in the receiver. Furthermore, a receiver must have a large area for reception and using an optical concentrator for achieving this. The optical concentrator might be considerably enhancing the effective signal receiving area, providing efficient noise-free gain, increasing the receiver's reception gain, and avoid utilizing a large PD surface area [34].

\section{Li-Fi WORKING PRINCIPLE}

In general, the white-colored LEDs were applied for executing $\mathrm{Li}-\mathrm{Fi}$ at the transmitter (downlink). Also, a current which is continuous and stable was utilized to those LEDs for enlightening LEDs. Currently, there was a parameter related to the Optical Yield that is of high importance to determine the factor of Li-Fi. Also, a current varying and rapidly shifting in nature might pass through it for irregularly changing it. Although slight variations in current, the optical output might be made for diverging rapidly at high-speed, such optical current characteristic is creating the base for setting up the connection of Li-Fi. The optical current activity was of high importance in the case when LED is in the "ON" configuration after that digital " 1 "e was transmitted and with situations in which LED is in "OFF" configurations after that digital " 0 "e was transmitted, such phenomenon happens at a fast rate which the glow which is related to LED isn't visible to the human eye. Thus, the license required to set up Li-Fi is a few LEDs and a controller to code data in LED. Also, the fact that few improvements might be made, such as utilizing a combination that is related to LED for carrying out the data transmission in parallel, was another vital aspect. The mixture related to LEDs of many colors, like red, green, and blue, might be utilized for the alteration of the frequency of light. The benefits of making such alterations were the tools that (hypothetically) ensuring a bit rate of approximately 10 gigabits for each second, indicating that an individual might simply download excellent quality video or a film of approximately 30 seconds [35] [36]. Fig 4 is showing the Li-Fi principle 


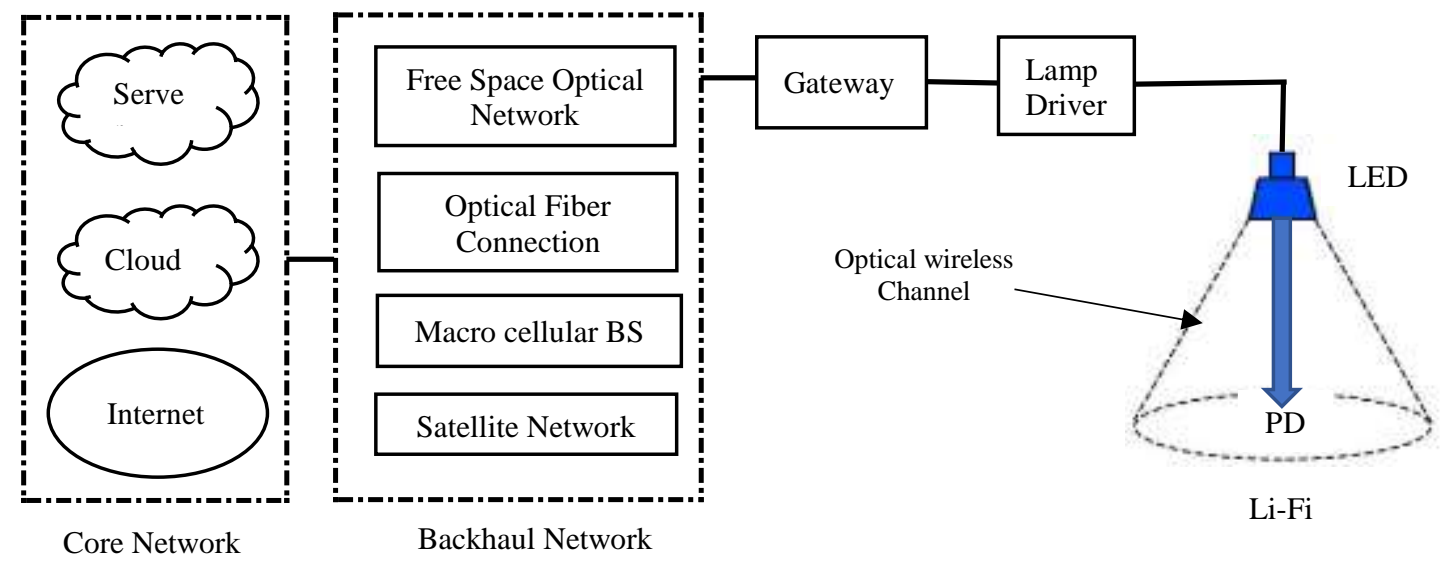

FIG. 4. WORK OF THE Li-Fi SYSTEM [36]

\section{Li-Fi ADVANTAGES}

The technology of Li-Fi is based on using a light source for data transmission and regardless of which part of the spectrum is used, visible or invisible. It supports the user with more than enough communication speed to download movies, music, games, and everything in extremely little time. Also, it is removing the limitations for the users of WiFi [38].

a. Capacity: There is 10,000 times more bandwidth in visible light in comparison to the radio waves' bandwidth [39].

b. Efficiency: Utilizing such technology for data transfer is extremely cheap. It is consuming not much energy and it is considered to be effective [39].

c. Availability: Light is available in a massive amount. Worldwide, there are millions of light bulbs; they must only be replaced with a suitable LED for the adequate functioning of such technology [39].

d. Security: As the waves of light cannot pass through opaque materials or walls, they might not be accessed via another individual sitting next door [39].

\section{- Benefit Li-Fi over Wi-Fi}

A comparison is given here between $\mathrm{Wi}-\mathrm{Fi}$ and $\mathrm{Li}-\mathrm{Fi}$, the transmitter and receiver area LED are used in the Li-Fi transmitter, while the antenna is used for $\mathrm{Wi}-\mathrm{Fi}$ and the Li-Fi receiver lights up while the Wi-Fi network contains an antenna. On the user side, the target users included in Li-Fi are all people under the lamp, while Wi-Fi depends on their access points, as Li-Fi covers a short area of $10 \mathrm{~m}$, whereas Wi-Fi ranging between 20 and 100 meters, depending on the type related to antenna and transmission capacity. However Li-Fi performance is better because LEDs consume less energy and were more effective, whereas Wi-Fi was less effective because of the more energy consumed via radio stations [40].

\section{Li-Fi CHALLENGES}

Li-Fi systems are more vulnerable to link blockage while Wi-Fi systems are robust to them, and the effect of blocking links is negligible. Because of the nature of the Li-Fi channel, an opaque object, like the human body or other comparable objects, can block the 
DOI: https://doi.org/10.33103/uot.ijccce.21.2.1

link between a pair of transmitters and receivers. However, mobile users in an indoor environment were the major cause related to link blocking as can be seen in Fig.5. [41]

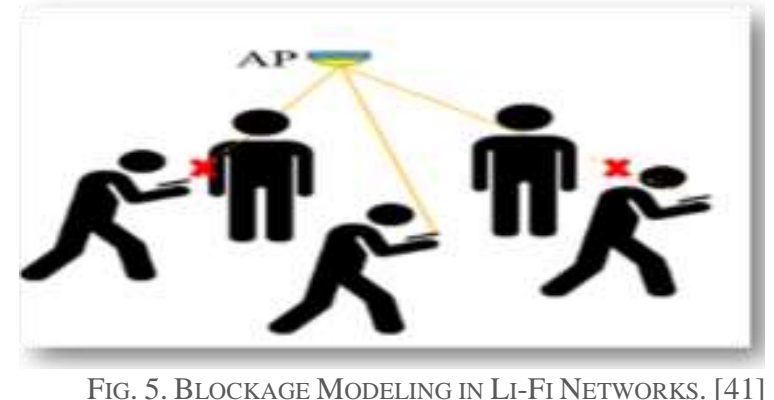

There are some problems with Li-Fi technology like security, coverage, capacity, availability, efficiency, and interruption [42].

a. For efficient data transmission, Li-Fi requires a sightline. The small difference results in transmission interruption.

b. The receiving apparatus shouldn't be relocated to the hall.

c. The receiving device doesn't know how to forward data back to the transmitter.

d. An external light source like opaque objects, sunlight, and ordinary bulbs might result in interference throughout data transmission. It results in diminishing reliability.

e. VLC cannot pierce through brick, thick walls like radio waves and just blocked via things, people, and so on.

\section{Li-Fi MODULATION TECHNIQUES}

Visible light was utilized via Li-Fi to send data; thus, the data might be modulated to a signal that will be transmitted through the wireless channel. Also, Li-Fi is providing many distinctive formats of modulation. The majority of modulation approaches utilized in $\mathrm{Li}-\mathrm{Fi}$ are indicated as follows:

\section{a. Single-Carrier Modulation (SCM):}

About Li-Fi, dimming-based modulation approaches, that were single carrier-based methods, in the case when the applications with low medium data rates have been proposed. Pulse Width Modulation (PWM), Pulse Position Modulation (PPM), On-Off Keying (OOK), Variable Pulse Position Modulation (OPPM), overlapping optical spatial modulation PPM (OSM), all of them are SCM systems [43] which can be used in the system of Li-Fi based on indoor systems [44] [45] [46]. OOK was majorly utilized since it might be implemented easily and offering an excellent tradeoff between complexity and system performance. About power, efficiency PPM was better compared to OOK, yet has low spectral efficiency compared to OOK. Optical spatial modulation is another utilized scheme of modulation. Also, $\mathrm{Li}-\mathrm{Fi}$ is effective regarding bandwidth and power for indoor wireless communications. One of the other modulation techniques utilized to transmit signals in one carrier Li-Fi system is Quadrature Amplitude Modulation (QAM) [7].

\section{b. Multi-Carrier Modulation (MCM):}

The results show that as with the increase in data rates because of Inter-symbol Interference (ISI), there will be degradation in the performance related to single-carrier methods. In comparison to SCM, the MCM was less energy efficient, yet it is considered to be more bandwidth efficient. OFDM is a major scheme utilized in MCM [22] [47]. Yet, it is 
DOI: https://doi.org/10.33103/uot.ijccce.21.2.1

bipolar and complex by nature, current, as well as the light emitted through the LED, was non-linear and such phenomena are affecting the performance of modulation systems based on OFDM [48] [49]. Also, a common OFDM modulator was achieved via taking Inverse Fast Fourier Transform (IFFT) and after that digital-to-analog (DAC) converter, while the created OFDM signal was bipolar and complex, yet the created OFDM signal was suggested to be of a real value signal for fitting the IM / DD (Intensity Modulation / Direct Detection) requirements. To get a real evaluated signal at output following IFFT, there is a requirement for taking Hermitian symmetry on sub-carriers. The light intensity cannot be negative and therefore the Li-Fi signal must be unipolar. Furthermore, the DOC-OFDM must be utilized for obtaining unipolar signals since it is using positive direct current (Dc) bias to generate unipolar signals which result in high consumption of power, yet with no impact on the spectral efficiency [7].

\section{Li-Fi APPLICATION}

The VLC's inherented features include no health hazard, high bandwidth, low power consumption, and unlicensed channels which make it attractive for practical usage. Various scenarios for applications with VLC are as follows:

a. Road Safety: OWC communication might be informing the on-board computer on a smart car of red traffic-lights, the lighting of brake lights or 3 flashing lights on the previous vehicle, and so on [50], as shown in Fig. ${ }^{7}$

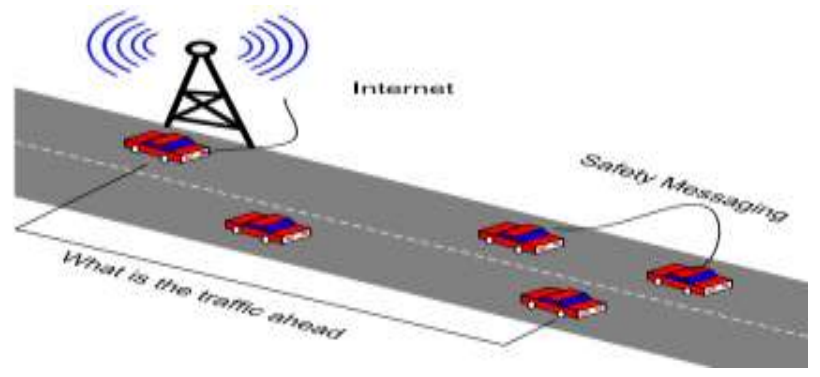

FIG. 6. VLC FOR VEHICULAR NETWORKS. [51]

b. Aviation: In-plane cabins, the LED lights were existing. To reduce cables, they might be combined with in-flight entertainment systems with the use of Li-Fi, this is going to decrease the weight of aircraft and simplifying the internal cabling design [50].

c. Medical Field: Coordinated in medical clinics and therapeutic devices, since it must be utilized in places in which there were restrictions on Wi-Fi, Internet, Bluetooth, and Infrared. Due to radiation concerns, Operation Theaters do not allow Wi-Fi. Li-Fi subsequently addresses two problems: its range is more compared to $\mathrm{Wi}-\mathrm{Fi}$, which might be significant for medical data, while lights were vital installations in the operation theatre, thus Li-Fi might be utilized for getting control over medical equipment and the web. Thus, it is significant for computerized approaches and mechanical medical processes [52].

d. Underwater communication: Remotely Operated Vehicle (ROV) submerged vehicles operating from large links and supplying power as well as allowing signals for being received via their pilots. However, the link utilized in ROVs isn't adequate for permitting them to investigate bigger regions. Also, their wires have been replaced by light say from powerful and submerged light, pilots will be much freer to investigate further at that point. It opens up space for military use in this way. [53]. Show in Fig 7. 

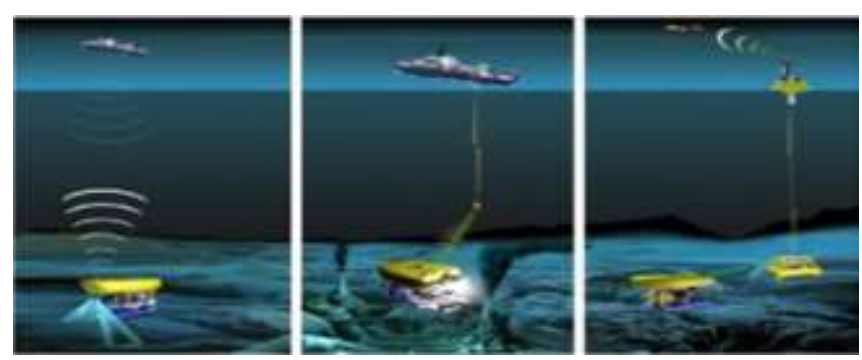

Fig. 7. SUBMARINE COMMUNICATION [53]

e. Industrial Purpose: Power plants are requiring fast, interrelated information models with the goal that requests, grid integrity, and central temperature may be observed. For delicate places involving power plants, particularly nuclear power plants, the wireless connections and various radiation types are harmful. For all of these fields, Li-Fi could provide a protected, inexhaustible network. When compared to the actual provisions, this will lower the expenditure. Similarly, it could decrease the stress on resources owned by power plants. It can also be used in oil plants where other transmissions or frequencies are usually risky [54].

f. Visible light ID system: The visible light in many places, like subways and buildings, might be utilized as an ID system. For example, in the case when standing in room 12 in a specific building. To identify the room number as well as construction, a visible light ID system might be utilized. In airports, hospitals, and subways, a visible light ID system might be comparable utilized [51]. show in Fig 8.

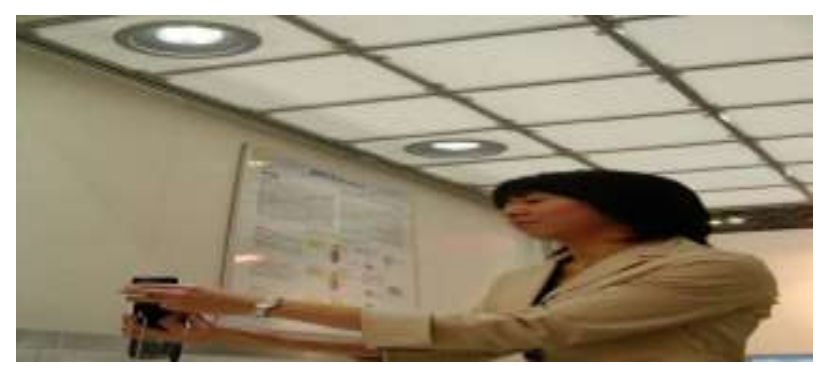

Fig. 8. Prototype PRovided Via NEC Electric Works AND Matsushita [51]

\section{CONCLUSION}

This paper has provided a review of Li-Fi technology. With this $\mathrm{Li}-\mathrm{Fi}$ technology, it may be seen that the Li-Fi is a sophisticated design method, which has the best internet design through the significant reduction in the device size, which transfers the implementation of the data through having over 1.4 million light bulbs worldwide, if substituted by those LEDs may result in providing feasible access. Li-Fi is far more secure and reliable compared with the traditional Wi-Fi architecture. Wi-Fi is subjected to security risks like the leakage of data and session hijacking, whereas the Li-Fi is of high security because of the property of light propagation which doesn't allow light waves to be penetrating opaque objects. In addition to that, the Li-Fi utilizes an unlicensed light wave's spectrum and almost an unlimited bandwidth. Those make Li-Fi technology accommodate a massive amount of devices that have quite a high data rate. Although there are some 
DOI: https://doi.org/10.33103/uot.ijccce.21.2.1

shortcomings, however, a careful further research can eliminate them. Li-Fi has provided a step forward in a world of increasing hunger communication, making it safe for all biodiversity, which includes humans, and moving toward a greener, brighter, and cheaper technology future. And it is helpful as well in 4G \& 5G technologies and broadband technologies with advanced upgrades.

\section{REFERENCES}

[1] Y. F. Ali.; FARHAN, Aqeel R. Spectral efficiency improvement of the optical communication systems. Ijccce, 2014.

[2] M. Hase, P. Bhanushali, P. Vora, P. Goswami, and M. A. K. Kerawalla, "Li-Fi-A revolution in the field of wirelesscommunication,” Int. J. Adv. Res. Eng. Appl. Sci, 2016.

[3] D. Dinev, V. Aleksieva, and H. Valchanov, "Study of Li-Fi Indoor Network Reliability," in 202021 st International Symposium on Electrical Apparatus \& Technologies (SIELA), 2020.

[4] N. AL-FALAHY, ALMAHAMDY, Mohammed; MAHMOOD, Ali M. Performance analysis of millimeter wave 5G networks for outdoor environment: propagation perspectives. Indonesian Journal of Electrical Engineering and Computer Science, 2020.

[5] M. A, M.; A. A; ALANI, Omar Y. Cognitive Neural Network Delay Predictor for High Speed Mobility in 5G C-RAN Cellular Networks. In: 2018 IEEE 5G World Forum (5GWF). IEEE, 2018.

[6] A. W. Riyadh, et al. Improved active disturbance rejection-based decentralized control for MIMO nonlinear systems: comparison with the decoupled control scheme. Applied Sciences, 2020.

[7] S. Jaafaru, et al. Review of Handover in Li-Fi and Wi-Fi Networks. In: International Conference on Computer Networks and Inventive Communication Technologies. Springer, Cham, 2019.

[8] W. Zhang, M. I. S. Chowdhury, and M. Kavehrad, "Asynchronous indoor positioning system based on visible light communications," Opt. Eng, 2014.

[9] Y. Zhou, Y. Xu, Z. Wang, N. Chi, and X. Lu, "MIMO VLC positioning system based on LEDs utilizing diversity reception technology," in International Conference on Wireless Communications \& Signal Processing (WCSP), 2015.

[10] T. T. Son, H. Le-Minh, F. Mousa, Z. Ghassemlooy, and N. Van Tuan, "Adaptive correction model for indoor MIMO VLC using positioning technique with node knowledge," in International Conference on Communications, Management and Telecommunications (ComManTel), 2015.

[11] A. Yesilkaya, E. Basar, F. Miramirkhani, E. Panayirci, M. Uysal, and H. Haas, "Optical MIMO-OFDM with generalized LED index modulation,” IEEE Trans. Commun, 2017.

[12] S. Fuada, A. P. Putra, and T. Adiono, "Analysis of received power characteristics of commercial photodiodes in indoor LoS channel visible light communication.”,2017.

[13] M. Al-Nassrawi, H. Le-Minh, Z. Ghassemlooy, T. T. Son, and M. Zhang, "Indoor positioning using single transmitter for visible light communications system," in First South American Colloquium on Visible Light Communications (SACVLC), 2017.

[14] K. Gligorić, M. Ajmani, D. Vukobratović, and S. Sinanović, "Visible light communications-based indoor positioning via compressed sensing," IEEE Commun, 2018.

[15] S. Zhang, P. Du, C. Chen, and W.-D. Zhong, "3D Indoor visible light positioning system using RSS ratio with neural network," in 23rd Opto-Electronics and Communications Conference (OECC), 2018.

[16] C. Lin et al., "An indoor visible light positioning system using artificial neural network," in Asia Communications and Photonics Conference (ACP), 2018.

[17] K. O. Akande, F. B. Offiong, H. Alrakah, and W. O. Popoola, "Performance comparison of MIMO cap receivers in visible light communication," in 11th International Symposium on Communication Systems, Networks \& Digital Signal Processing (CSNDSP), 2018.

[18] N. Lorrière et al., "An OFDM testbed for LiFi performance characterization of photovoltaic modules," in Global LIFI Congress (GLC), 2018.

[19] B. Rui; TAVAKKOLNIA, Iman; HAAS, Harald. $15.73 \mathrm{~Gb} / \mathrm{s}$ visible light communication with off-the-shelf LEDs. Journal of Lightwave Technology, 2019, 37.10: 2418-2424.

[20] M. D. Soltani, A. A. Purwita, I. Tavakkolnia, H. Haas, and M. Safari, "Impact of device orientation on error performance of LiFi systems," IEEE Access, 2019.

[21] Di. Kumari and S. Singh, "Performance Analysis of DC-OFDM Modulation Scheme in Li-Fi Communication System," 2020 IEEE Int.

[22] M. R. Mallick, "A comparative study of wireless protocols with Li-Fi technology: A survey," in Proceedings of 43rd IRF International Conference, 2016.

[23] G. A. Naidu and J. Kumar, "Wireless Protocols: Wi-Fi SON, Bluetooth, ZigBee, Z-Wave, and Wi-Fi," in Innovations in Electronics and Communication Engineering, Springer, 2019. 
DOI: https://doi.org/10.33103/uot.ijccce.21.2.1

[24] Z. N. Abdul Khaleq; CROOCK, Muayad Sadik; TARESH, Ali Abdul Razzaq. Indoor Localization System Using WiFi Technology. IRAQI JOURNAL OF COMPUTERS, COMMUNICATION, CONTROL \& SYSTEMS ENGINEERING, 2019.

[25] M. S. Balan, S. Musale, R. Saptarshi, P. Sawant, S. Somwanshi, and P. Zadge, "Comparative Study and Performance Evolution of Wireless Data Transmission Techniques for an Integrated Bathymetry Survey for Reservoir," Int. J. Comput. Appl, 2015.

[26] A. J. SALIM, et al. A polygonal open-loop resonator compact bandpass filter for Bluetooth and WLAN applications. In: IOP Conference Series: Materials Science and Engineering. IOP Publishing, 2018.

[27] P. Aruna and N. Vetrivelan, "Survey and Comparative Study of Wireless Technologies for Enchanced MANET," Int. J. Appl. Eng. Res, 2015.

[28] K. Ekhlas; HAITHAM, Russul. Performance Analysis of IEEE 802.15. 4 Transceiver System under Adaptive White Gaussian Channel. International Journal of Electrical \& Computer Engineering (2088-8708), 2018.

[29] R. George, S. Vaidyanathan, A. S. Rajput, and K. Deepa, "LiFi for Vehicle to Vehicle Communication-A Review," Procedia Comput. Sci, 2019.

[30] J., Noor J.; SATAR, Sinan M. Abdul. Optical Camera Communication Performance Evaluation. IRAQI JOURNAL OF COMPUTERS, COMMUNICATION, CONTROL \& SYSTEMS ENGINEERING, 2020

[31] T. , Zainab H., et al. Structural, Morphological and Optical Properties of Gold Nanoparticles Using Laser Ablation in Liquid for Sensor Applications. IRAQI JOURNAL OF COMPUTERS, COMMUNICATION, CONTROL \& SYSTEMS ENGINEERING, 2019.

[32] Y. Perwej, "The next generation of wireless communication using Li-Fi (Light Fidelity) technology," J. Comput. Networks, 2017.

[33] N. V. Swami, "Li-Fi (LIGHT FIDELITY)_-THE changing scenario of wireless communication," Int J Res Eng Technol, 2015.

[34] Y. Qiu, H. Chen, and W. Meng, "Channel modeling for visible light communications-a survey," Wirel. Commun. Mob. Comput, 2016.

[35] A. D. Kumar and S. Smys, "An energy efficient and secure data forwarding scheme for wireless body sensor network," Int. J. Netw. Virtual Organ], 2019.

[36] C. W. D. Lumoindong, A. Muslim, B. M. Nasreddin, and M. Galina, "Performance and environmental impacts review of Li-Fi and Wi-Fi technologies," J. Environ. Eng. Waste Manag, 2018.

[37] AL-RUBAYE, Saba, et al. Industrial internet of things driven by SDN platform for smart grid resiliency. IEEE Internet of Things Journal, 2017.

[38] S. L. Wakchaure, S. D. Pawar, V. V Thitme, and B. B. Shinde, "Overview of Li-Fi Technology," Int. Res. J. Eng. Technol, 2017.

[39] R. Johri, "Li-Fi, complementary to Wi-Fi," in International Conference on Computation of Power, Energy Information and Commuincation (ICCPEIC), 2016.

[40] A. A. Shuriji, "An extensive comparison of the next generation of wireless communication technology: Light-fidelity (Li-Fi) versus wireless-fidelity (Wi-Fi)," GSTF J. Media Commun, 2014.

[41] N. Soni, M. Mohta, and T. Choudhury, "The looming visible light communication Li-Fi: An edge over Wi-Fi," in international conference system modeling \& advancement in research trends (SMART), 2016.

[42] X. Wu, M. D. Soltani, L. Zhou, M. Safari, and H. Haas, "Hybrid LiFi and WiFi Networks: A Survey," 2020.

[43] S, Wafaa Mohammed R.; SADKHAN, Sattar B.; AKKAR, Hanan. BPSK receiver based on independent component analysis. In: 2012 International Conference on Future Communication Networks. IEEE, 2012.

[44] P. Kuppusamy, S. Muthuraj, and S. Gopinath, "Survey and challenges of Li-Fi with comparison of Wi-Fi," in International Conference on Wireless Communications, Signal Processing and Networking (WiSPNET), 2016.

[45] Z, R. Dhafer; ABDULlAH, Hadeel N.; FARHAN, Ikhlas M. A Review for the Adopted Techniques in Low SNR Communication Systems. IRAQI JOURNAL OF COMPUTERS, COMMUNICATION, CONTROL \& SYSTEMS ENGINEERING, 2020.

[46] H., Hamood Shehab; ISMAIL, W.; SINGH, M. Analyze BER performance of wireless FSK system. Microwaves and RF, 2009.

[47] N. A. Kareem; GAZALI, KH Bin. Local search particle swarm optimization algorithm channel estimation based on MC-CDMA system. ARPN Journal of Engineering and Applied Sciences, 2015.

[48] M. Irshad, W. Liu, L. Wang, S. B. H. Shah, M. N. Sohail, and M. M. Uba, "Li-local: green communication modulations for indoor localization," in Proceedings of the 2nd International Conference on Future Networks and DistriHowever ed Systems, 2018.

[49] H., Mohammed A.; NAHAR, Ali K.; ALA'A, H. Ali. A new hybrid approach for reducing the high PAPR in OFDM and F-OFDM systems with low complexity. In: 2020 2nd Al-Noor International Conference for Science and Technology (NICST). IEEE, 2020.

[50] G. S. Spagnolo, L. Cozzella, F. Leccese, S. Sangiovanni, L. Podestà, and E. Piuzzi, "Optical Wireless Communication and Li-Fi: a New Infrastructure for Wireless Communication in Saving Energy Era," in IEEE International Workshop 
DOI: https://doi.org/10.33103/uot.ijccce.21.2.1

on Metrology for Industry 4.0 \& IoT, 2020.

[51] L. U. Khan, "Visible light communication: Applications, architecture, standardization and research challenges," Digit. Commun. Networks, 2017.

[52] X. Wu, M. Safari, and H. Haas, “Access point selection for hybrid Li-Fi and Wi-Fi networks," IEEE Trans. Commun, 2017.

[53] X. Wu, M. Safari, and H. Haas, “Access point selection for hybrid Li-Fi and Wi-Fi networks,” IEEE Trans. Commun, 2017.

[54] J., Esha; K., Deepak. A Review Paper on Li-Fi Technology. International Journal of Scientific \& Engineering Research, 2015. 